\title{
Comprehensive Review on Non-Surgical Periodontal Therapy
}

\author{
P. Keshaav Krishnaa ${ }^{1}$, R. Arvina ${ }^{2}$ \\ 1Department of Periodontology, Saveetha Dental College, Saveetha Institute of Medical and Technical \\ Sciences, Chennai, Tamilnadu, India. ${ }^{2}$ Department of Periodontology, Saveetha Dental College, Saveetha \\ Institute of Medical and Technical Sciences, Chennai, Tamilnadu, India.
}

\section{ABSTRACT}

Periodontitis is one the most common diseases of the oral cavity and affects majority of the population. In the recent times there have been several advances in the treatment modalities for the same. One of the most common aetiological factors for the disease is dental plaque. Thus, the aim of various therapeutic options is the elimination of dental plaque. The methods range from something as simple as tooth brushing and oral hygiene practices to those administered by a dental professional. There are various mechanical methods and chemical methods for the same. There are also certain methods like the usage of local drug delivery and mouthwashes that can be used as adjuncts to any type of periodontal therapy. The treatment modalities can be surgical or non-surgical. With the patient being kept at the centre of the equation, non-surgical periodontal therapy is more acceptable to the patient and is also easy to perform and not very complex. In the present review, various options for the management of periodontal disease through non-surgical periodontal therapy have been addressed along with recent advances towards the same.

\section{KEY WORDS}

Non-Surgical Periodontal Therapy (NSPT), Gingivitis, Treatment
Corresponding Author:

P. Keshaav Krishnaa,

\#163, Poonamallee High Road,

Velappanchavadi, Tamilnadu, India.

E-mail: keshaav.krishnaa.98@gmail.com

DOI: $10.14260 /$ jemds/2020/577

How to Cite This Article:

Krishnaa PK, Arvina R. Comprehensive review on non-surgical periodontal therapy. J Evolution Med Dent Sci 2020;9(36):2658-2662, 10.14260/jemds/2020/577

Submission 11-04-2020,

Peer Review 16-07-2020,

Acceptance 22-07-2020,

Published 07-09-2020.

Copyright (C) 2020 JEMDS. This is an open access article distributed under Creative Commons Attribution License [Attribution 4.0 International (CC BY 4.0)] 


\section{BACKGROUND}

Periodontitis is a chronic inflammatory disease affecting both hard and soft tissues of the oral cavity. ${ }^{1-3}$ Periodontitis is the second most prevalent dental disease next to dental caries. Periodontitis results in a progressive destruction of the periodontal fiber apparatus and parts of the alveolar bone with subsequent and sequential migration of the junctional epithelium apical to the tooth surface. ${ }^{4}$ One of the most common and prevalent aetiology of the disease is the accumulation of bacterial plaque. ${ }^{5,6}$ Consequently, the aim of the various therapeutic approaches that are available is to eliminate bacterial plaque.

Mechanical plaque removal, using curettes and ultrasonic devices, has become a well-documented and effective treatment modality.7,8 In addition, various attempts to eliminate pathogenic bacteria by mouth rinses and additive administration of local and systemic antibiotics have been explored.9-14 Topical application of antiseptics in periodontal pockets as an adjunctive to mechanical debridement has also been suggested ${ }^{15,16}$ and tested in various clinical trials, ${ }^{17,18}$ but there is still a lack of clear evidence for its additional benefit. ${ }^{19}$ 21 This review highlights the various non-surgical treatment modalities of periodontal disease.

\section{Oral Hygiene Practices}

Tooth brushing is the method which most of the individuals use for their daily oral hygiene. However, it appears that most patients are unable to achieve sufficient total plaque control at each brushing. Van der Weijden and Hioe. ${ }^{22}$ in a systematic review, assessed the effect of mechanical plaque control in adults with gingivitis and concluded that the quality of selfperformed mechanical plaque removal was not sufficiently effective and should be improved. From this review, it reflects that single oral hygiene instruction exercise describing the correct use of a mechanical toothbrush in addition to a single professional session of standard oral prophylaxis has a significant, albeit small, positive effect on the Gingival health.

New technologies such as powered toothbrushes have been developed that may enhance plaque removal and simplify the task. The powered toothbrushes have multiple advantages and have the inherent potential to enhance both plaque removal as well as patient motivation. Two systematic reviews investigated the superiority of powered toothbrushes over the manual toothbrushes and evaluated the efficiency of cleaning among different types of powered toothbrushes. ${ }^{23,24}$ Within the limits of These reviews they concluded that the powered toothbrushes with a rotational force has an oscillation action to reduce plaque and gingivitis greater than manual toothbrushes.

Recently new technologies of electric toothbrushes (e.g. sonic) have been introduced but their effect has not been systematically reviewed yet.24 The results of another systematic review by Sicilia et al. are in line with the above conclusions. ${ }^{25}$ On the other hand, Deery et al. ${ }^{26}$ found no evidence of a statistically significant difference between powered and manual brushes. However, rotation oscillation powered brushes were shown able to significantly reduce plaque and gingivitis in both the short and long-term. Contrary to the above results, Deacon et al. ${ }^{27}$ in a more recent Cochrane systematic review could not come to definitive conclusions regarding the superiority of one mode of powered toothbrush over any other. The need of further good quality randomised controlled clinical trials was emphasized.

Addition of several chemical agents in toothpastes aims to reduce plaque and gingival inflammation. Among them the stannous fluoride and triclosan-containing toothpastes demonstrated a better antiplaque and antigingivitis effect than conventional dentifrice. ${ }^{28,29}$ Slot et al. ${ }^{30}$ systematically reviewed the literature investigating the antiplaque and antigingivitis properties of chlorhexidine gel and dentifrice. The evidence for the chlorhexidine gel was not conclusive. On the other hand, although brushing with a chlorhexidine dentifrice was shown to be effective, the related tooth discoloration may have a negative impact on patient's compliance.

Chemical plaque control has been proposed as part of an oral hygiene regimen. However, it cannot replace the mechanical self-performed plaque control. According to Gunsolley 31 who performed a meta-analysis of six-month studies of antiplaque and antigingivitis agents, the largest sum of studies was for the efficacy of mouth rinses with essential oils and a minority of the population supported a strong antiplaque and antigingivitis effect of $0.12 \%$ chlorhexidine. The findings were inconsistent for mouth rinses containing cetylpyridinium chloride. In a recent systematic review, Berchier et al. ${ }^{32}$ showed a small but significant plaque inhibition effect of $0.2 \%$ chlorhexidine versus the $0.12 \%$ mouthwash. However, the clinical effect of this difference is probably very small.

Interdental cleaning is supposed to be essential to improve and maintain gingival health. The interdental areas cannot be reached by toothbrushes alone. Several aids have been used and investigated for their effectiveness such as floss, toothpicks and interdental brushes. Many dentists would confess that daily flossing is of paramount importance for maintaining good oral health. However, the ability of individuals to perform high quality flossing is questionable. There is small evidence that flossing in addition to toothbrushing reduces gingivitis but the evidence regarding plaque reduction is weak and unreliable. Therefore, the routine instruction for daily flossing is not supported by scientific evidence and should be given only on an individual patient basis when high quality flossing could be achievable. ${ }^{33,34}$ The use of wood sticks does not have an additional effect on visible interdental plaque or gingival index. $^{35}$ Interdental brushes have been shown to be the most effective interdental cleaning aids. A systematic review by Slot et al. ${ }^{36}$ demonstrated a significant positive difference using interdental brushes in plaque and bleeding scores and probing pocket depth. Use of interdental brushes in conjunction with brushing removes more plaque than brushing alone and brushes appear to be superior to flossing.

Lastly, oral irrigators are another aid proposed as adjuncts of tooth brushing. Although there is evidence suggesting that oral irrigating reduces signs of gingival inflammation and improves gingival health, it has no beneficial effect in reducing visible plaque. ${ }^{37}$ 


\section{Periodontal Instrumentation}

Historically, one of the main objectives of the periodontal instrumentation was the removal of the infected cementum. Therefore, vigorous hand instrumentation and root planing was required to remove part of the cementum and achieve a smooth root surface. However, it was shown that microbial endotoxins are not strongly adhered on the root surface and that betterment in periodontal health can be accomplished without the removal of cementum by scaling and root planning procedures. $^{38,39}$ The term periodontal debridement was suggested by Smart et al. to describe the light overlapping strokes used for instrumenting the tooth with a sonic or ultrasonic scaler. ${ }^{40}$ Subsequently, the term has been used more broadly to describe the gentle but thorough instrumentation (by power driven and hand scaling) aiming at the removal of plaque, endotoxin and calculus but not cementum. In vivo and in vitro studies indicate that the loss of root substance and the roughness of root surface is less following ultrasonic than manual root instrumentation. ${ }^{41,42}$

\section{Hand Scaling vs Ultrasonic Scaling}

A systematic review by Tunkel et al. ${ }^{43}$ investigating the efficacy of machine driven and manual subgingival debridement failed to demonstrate any significant difference between the two methods. These results are in line with those from a later systematic review by Hallmon and Rees et al. ${ }^{44} \mathrm{~A}$ latest development in ultrasonic scaling systems is the Vector $\AA$, marketed as a pain free ultrasonic scaler. This device is effective and generates vibrations at a frequency of about 25 $\mathrm{kHz}$ resulting in a parallel movement of the working tip at the level of the root surface. Slot et al conducted a systematic review and concurred that the Vector $\AA$ provides comparable clinical and microbiological results as power-driven and manual instrumentation in moderately deep periodontal pockets, but it is less effective in deep pockets and it requires considerably more amount of time for calculus removal. 45

\section{Laser Irradiation Therapy}

Laser mediated therapy is also an upcoming aspect of nonsurgical periodontal therapy. The most widely used type of laser as a replacement for scaling or an adjuvant for scaling is ER-YAG laser. ${ }^{46}$ In a study conducted by Schwarz et al. ${ }^{47}$ compared the efficacy of scaling procedure using scalers and laser and was found that there was no statistical difference in the improvement in periodontal health of the patient. But nevertheless usage of laser proved to be atraumatic and hence benefit the patient and provide good clinical results.

\footnotetext{
Antimicrobial Therapy

It has been suggested that root debridement alone is insufficient to eliminate bacteria that have invaded the soft tissue. Because most of the periodontal pathogens involved in the destruction process are tissue invading organisms. ${ }^{48,49}$ Therefore, systemic administration of antibiotics as adjunct to root debridement has been suggested. Systemic antimicrobials in conjunction with scaling and root planing offer an additional clinical benefit in probing depth reduction and clinical attachment gain. 50,51 The results of a meta-analysis by Hayes et al., however, did not demonstrate an additional benefit of
}

the systemic administration of tetracycline. ${ }^{52}$ Similarly, Elter et al. suggested that the additional benefit of the systemic metronidazole was not evident after a thirteen week follow-up period. ${ }^{53}$ Contrary to the above findings a recent systematic review and meta-analysis seems to support the combined systemic administration of amoxicillin and metronidazole adjunctively to scaling and root planning. ${ }^{54}$ Other than systemic antibiotics, localised antibiotics has also been investigated as an adjunct to scaling. ${ }^{55,56}$

\section{Local Drug Delivery}

The local drug delivery system is in which the drug injected into the gingival sulcus. The main antimicrobial agents employed in the drug delivery systems are tetracyclines (tetracycline hydrochloride, doxycycline, minocycline). ${ }^{57}$ several studies have addressed other potential benefits of tetracycline fibers. Lowenguth et al. ${ }^{58}$ and Michalowicz et al. ${ }^{59}$ found that combined therapy resulted in less sites with disease progression and development than after scaling and root planing procedure alone during a 1 -year monitoring period.

\section{CONCLUSIONS}

Periodontal diseases are one of the most commonly seen diseases of the oral cavity. This review covers all non-surgical periodontal therapies, which should be considered as first line measures for treating periodontal disease before resorting to surgical approaches.

Financial or Other Competing Interests: None.

\section{REFERENCES}

[1] Loe H. Principles of aetiology and pathogenesis governing the treatment of periodontal disease. Int Dent J 1983;33(2):119-26.

[2] Oliver RC, Brown LJ, Loe H. Periodontal diseases in the United States population. J Periodontol 1998;69(2):26978.

[3] Albandar JM, Rams TE. Global epidemiology of periodontal diseases: an overview. Periodontol 2000 2002;29:7-10

[4] Flemmig TF. Periodontitis. Ann Periodontol 1999;4(1):32-38.

[5] Socransky SS. Microbiology of periodontal disease -present status and future considerations. J Periodontol 1977;48(9):497-504.

[6] Consensus report. Periodontal diseases: pathogenesis and microbial factors. Ann Periodontol 1996;1(1):926-32.

[7] Badersten A, Nilveus R, Egelberg J. Effect of nonsurgical periodontal therapy. I. Moderately advanced periodontitis. J Clin Periodontol 1981;8(1):57-72.

[8] Westfelt E, Bragd L, Socransky SS, et al. Improved periodontal conditions following therapy. J Clin Periodontol 1985;12(4):283-93.

[9] Haffajee AD, Socransky SS, Gunsolley JC. Systemic antiinfective periodontal therapy. A systematic review. Ann Periodontol 2003;8(1):115-81. 
[10] Herrera D, Sanz M, Jepsen S, et al. A systematic review on the effect of systemic antimicrobials as an adjunct to scaling and root planing in periodontitis patients. J Clin Periodontol 2002;29(3):136-59.

[11] Haffajee AD, Dibart S, Kent RL, et al. Clinical and microbiological changes associated with the use of 4 adjunctive systemically administered agents in the treatment of periodontal infections. J Clin Periodontol 1995;22(8):618-27.

[12] Clark DC, Shenker S, Stulginski P, et al. Effectiveness of routine periodontal treatment with and without adjunctive metronidazole therapy in a sample of mentally retarded adolescents. J Periodontol 1983;54(11):658-65.

[13] Soder PO, Frithiof L, Wikner S, et al. The effect of systemic metronidazole after non-surgical treatment in moderate and advanced periodontitis in young adults. J Periodontol 1990;61(5):281-8.

[14] Mombelli A, Samaranayake LP. Topical and systemic antibiotics in the management of periodontal diseases. Int Dent J 2004;54(1):3-14.

[15] Rosling BG, Slots J, Webber RL, et al. Microbiological and clinical effects of topical subgingival antimicrobial treatment on human periodontal disease. J Clin Periodontol 1983;10(5):487-514.

[16] Shiloah J, Hovious LA. The role of subgingival irrigations in the treatment of periodontitis. J Periodontol 1993;64(9):835-43.

[17] Oosterwaal PJ, Mikx FH, van't Hof MA, et al. Comparison of the antimicrobial effect of the application of chlorhexidine gel, amine fluoride gel and stannous fluoride gel in debrided periodontal pockets. J Clin Periodontol 1991;18(4):245-51.

[18] von Ohler C, Weiger R, Decker E, et al. The efficacy of a single pocket irrigation on subgingival microbial vitality. Clin Oral Investig 1998;2(2):84-90.

[19] Drisko CL, Cochran DL, Blieden T, et al. Position paper: sonic and ultrasonic scalers in periodontics. Research, Science and Therapy Committee of the American Academy of Periodontology. J Periodontol 2000;71(1):1792-801.

[20] Greenstein G. Position paper: the role of supra- and subgingival irrigation in the treatment of periodontal diseases. J Periodontol 2005;76(11):2015-27.

[21] Guarnelli ME, Franceschetti G, Manfrini R, et al. Adjunctive effect of chlorhexidine in ultrasonic instrumentation of aggressive periodontitis patients: a pilot study. J Clin Periodontol 2008;35(4):333-41.

[22] van der Weijden GA, Hioe KP. A systematic review of the effectiveness of self-performed mechanical plaque removal in adults with gingivitis using a manual toothbrush. J Clin Periodontol 2005;32 Suppl 6:214-28.

[23] Heanue M, Deacon SA, Deery C, et al. Manual versus powered toothbrushing for oral health. Cochrane Database Syst Rev 2003;(1):CD002281.

[24] Robinson PG, Deacon SA, Deery C, et al. Manual versus powered toothbrushing for oral health. Cochrane Database Syst Rev 2005;(2):CD002281.

[25] Sicilia A, Arregui I, Gallego M, et al. A systematic review of powered vs manual toothbrushes in periodontal causerelated therapy. J Clin Periodontol 2002;29 Suppl 3:39-54.
[26] Deery C, Heanue M, Deacon S, et al. The effectiveness of manual versus powered toothbrushes for dental health: a systematic review. J Dent 2004;32(3):197-211.

[27] Deacon SA, Glenny AM, Deery C, et al. Different powered toothbrushes for plaque control and gingival health. Cochrane Database Syst Rev 2010;(12):CD004971.

[28] Hioe KP, Van der Weijden GA. The effectiveness of selfperformed mechanical plaque control with triclosan containing dentifrices. Int J Dent Hyg 2005;3(4):192-204.

[29] Paraskevas S, van der Weijden GA. A review of the effects of stannous fluoride on gingivitis. J Clin Periodontol 2006;33(1):1-13.

[30] Gunsolley JC. A meta-analysis of six-month studies of antiplaque and antigingivitis agents. J Am Dent Assoc 2006;137(12):1649-57.

[31] Slot D, Berchier CE, Addy M, et al. The efficacy of chlorhexidine dentifrice or gel on plaque, clinical parameters of gingival inflammation and tooth discoloration: a systematic review. Int J Dent Hyg 2013;12(1):25-35.

[32] Berchier CE, Slot DE, Van der Weijden GA. The efficacy of $0.12 \%$ chlorhexidine mouthrinse compared with $0.2 \%$ on plaque accumulation and periodontal parameters: a systematic review. J Clin Periodontol 2010;37(9):829-39.

[33] Berchier CE, Slot DE, Haps S, et al. The efficacy of dental floss in addition to a toothbrush on plaque and parameters of gingival inflammation: a systematic review. Int J Dent Hyg 2008;6(4):265-79.

[34] Sambunjak D, Nickerson JW, Poklepovic T, et al. Flossing for the management of periodontal diseases and dental caries in adults. Cochrane Database Syst Rev 2011;(12):CD008829.

[35] Hoenderdos NL, Slot DE, Paraskevas S, et al. The efficacy of woodsticks on plaque and gingival inflammation: a systematic review. Int J Dent Hyg 2008;6(4):280-9.

[36] Slot DE, Dorfer CE, Van der Weijden GA. The efficacy of interdental brushes on plaque and parameters of periodontal inflammation: a systematic review. Int J Dent Hyg 2008;6(4):253-64.

[37] Husseini A, Slot DE, Van der Weijden GA. The efficacy of oral irrigation in addition to a toothbrush on plaque and the clinical parameters of periodontal inflammation: a systematic review. Int J Dent Hyg 2008;6(4):304-14.

[38] Apatzidou DA. Modern approaches to non-surgical biofilm management. Front Oral Biol 2012;15:99-116.

[39] Drisko CH. Nonsurgical periodontal therapy. Periodontol 2000 2001;25(1):77-88.

[40] Smart GJ, Wilson M, Davies EH, et al. The assessment of ultrasonic root surface debridement by determination of residual endotoxin levels. J Clin Periodontol 1990;17(3):174-8.

[41] Marda P, Prakash S, Devaraj CG, et al. A comparison of root surface instrumentation using manual, ultrasonic and rotary instruments: an in vitro study using scanning electron microscopy. Indian J Dent Red 2012;23(2):16470.

[42] Santos FA, Pochapski MT, Leal PC, et al. Comparative study on the effect of ultrasonic instruments on the root surface in vivo. Clin Oral Investig 2008;12(2):143-50. 
[43] Tunkel J, Heinecke A, Flemmig TF. A systematic review of efficacy of machine-driven and manual subgingival debridement in the treatment of chronic periodontitis. J Clin Periodontol 2002;29 Suppl 3:72-81.

[44] Hallmon WW, Rees TD. Local anti-infective therapy: mechanical and physical approaches. A systematic review. Annals of Periodontology 2003;8(1):99-114.

[45] Slot DE, Koster TJG, Paraskevas S, et al. The effect of the Vector scaler system on human teeth: a systematic review. Int J Dent Hyg 2008;6(3):154-65.

[46] Bains VK, Gupta S, Bains R. Lasers in periodontics: an overview. J Oral Health Community Dent 2010;4:29-34.

[47] Schwarz F, Sculean A, Berakdar M, et al. Clinical evaluation of an Er: YAG laser combined with scaling and root planing for non-surgical periodontal treatment. A controlled, prospective clinical study. J Clin Periodontol 2003;30(1):26-34.

[48] Krayer JW, Leite RS, Kirkwood KL. Non-surgical chemotherapeutic treatment strategies for the management of periodontal diseases. Dent Clin North Am 2010;54(1):13-33.

[49] Mombelli A, Cionca N, Almaghlouth A. Does adjunctive antimicrobial therapy reduce the perceived need for periodontal surgery? Periodontol 2000 2011;55(1):20516.

[50] Haffejee AD, Socransky SS, Gunsolley JC. Systemic antiinfective periodontal therapy. A systematic review. Ann Periodontol 2003;8(1):115-81.

[51] Herrera D, Alonso B, León R, et al. Antimicrobial therapy in periodontitis: the use of systemic antimicrobials against the subgingival biofilm. J Clin Periodontol 2008;35(8 Suppl):45-66.
[52] Hayes C, Antczak-Bouckoms A, Burdick E. Quality assessment and meta-analysis of systemic tetracycline use in chronic adult periodontitis. J Clin Periodontol 1992;19(3):164-8.

[53] Elter JR, Lawrence HP, Offenbacher S, et al. Meta-analysis of the effect of systemic metronidazole as an adjunct to scaling and root planing for adult periodontitis. J Periodontol Res 1997;32(6):487-96.

[54] Sgolastra F, Gatto R, Petrucci A, et al. Effectiveness of systemic amoxicillin/metronidazole as adjunctive therapy to scaling and root planing in the treatment of chronic periodontitis: a systematic review and metaanalysis. J Periodontol 2012;83(10):1257-69.

[55] Hanes PJ, Purvis JP. Local anti-infective therapy: pharmacological agents. A systematic review. Ann Periodontol 2003;8(1):79-98.

[56] Bonito AJ, Lux L, Lohr KN. Impact of local adjuncts to scaling and root planing in periodontal disease therapy: a systematic review. J Periodontol 2005;76(8):1227-36.

[57] Sutter VL, Jones MJ, Ghoneim AT. Antimicrobial susceptibilities of bacteria associated with periodontal diseases. Antimicrob Agents Chemother 1983;23(3):4836.

[58] Lowenguth RA, Caton JG, Chin I, et al. Evaluation of periodontal treatments using controlled-release tetracycline fibers: microbiological response. J Periodontol 1995;66(8):700-7.

[59] Michalowicz BS, Pihlstrom BL, Drisko CL, et al. Evaluation of periodontal treatments using controlled-release tetracycline fibers: maintenance response. J Periodontol 1995;66(8):708-15. 